\title{
Preface to the Special Issue on "Applications of Fuzzy Optimization and Fuzzy Decision Making"
}

\author{
Vassilis C. Gerogiannis
}

check for updates

Citation: Gerogiannis, V.C. Preface to the Special Issue on "Applications of Fuzzy Optimization and Fuzzy Decision Making". Mathematics 2021, 9, 3009. https://doi.org/10.3390/ math9233009

Received: 16 November 2021 Accepted: 20 November 2021 Published: 24 November 2021

Publisher's Note: MDPI stays neutral with regard to jurisdictional claims in published maps and institutional affiliations.

Copyright: (C) 2021 by the author. Licensee MDPI, Basel, Switzerland. This article is an open access article distributed under the terms and conditions of the Creative Commons Attribution (CC BY) license (https:/ / creativecommons.org/licenses/by/ $4.0 /)$.
Department of Digital Systems, Faculty of Technology, University of Thessaly, Geopolis Campus, 41500 Larissa, Greece; vgerogian@uth.gr

During the last decades, fuzzy optimization and fuzzy decision making have gained significant attention, aiming to provide robust solutions for problems in making decisions and achieving complex optimization characterized by non-probabilistic uncertainty, vagueness, ambiguity and hesitation. The objective of this Special Issue is to expand the applicability of fuzzy optimization and decision making by applying state-of-the-art techniques from fuzzy technology, computational intelligence and soft-computing methodologies for solving real-life problems. The response of the scientific community has been significant, with many papers being submitted for consideration, and, finally, eighteen papers were accepted, after going through a careful peer-review process based on quality and novelty criteria.

The paper by Zhang et al. [1] proposes a case-based reasoning method for the judgment of debtor's hidden property analysis, which employs crisp and interval numbers as well as fuzzy linguistic variables, and develops a hybrid similarity measure to improve the efficiency of handling law enforcement cases.

The paper authored by Wu et al. [2] studies the energy-saving effects brought by yield improvement in a factory and proposes a two-stage fuzzy approach to estimate the energy savings. The actual case of a dynamic random-access memory factory was used to illustrate that product yield learning can greatly reduce electricity consumption.

The paper by Lefevr et al. [3] studies HIV spreading with fuzzy-based simulation scenarios by employing the observation and analysis of real-world networks and by introducing a fuzzy implementation of epidemic models. The simulation results demonstrate that the existence of fuzziness plays an important role in analyzing the effects of the disease spread.

In the paper by Yiğit et al. [4] the performance and efficiency of energy supply companies with respect to productivity are examined with reference to a case study of an electricity distribution company. The factors and their corresponding weights have been determined using the analytical hierarchy process (AHP) and the Fuzzy AHP methods.

In the paper authored by Poczeta et al. [5], the main idea is to systematically create a nested structure, based on a fuzzy cognitive map (FCM), in which each element/concept at a higher map level is decomposed into another FCM that provides a more detailed and precise representation of complex time series data.

Drakopoulos et al. [6] study cognitive graphs, which are effective tools for simultaneous dimensionality reduction and visualization in deep learning. In this paper, fuzzy cognitive graphs have been proposed for representing maps with incomplete knowledge or errors caused by noisy or insufficient observations. The study presents the construction of a cognitive map with a tensor distance metric, as well as a fuzzy variant of the map.

Wu et al. [7], propose a varying partial consensus fuzzy collaborative intelligence approach to assess an intervention strategy for tackling the COVID-19 pandemic. In the varying partial consensus fuzzy collaborative intelligence approach, multiple decision-makers express their judgments on the relative priorities of factors critical to an intervention strategy. 
The paper authored by Kim and Jung [8] proposes an $\alpha$-level estimation algorithm for ridge fuzzy regression modeling, addressing the multicollinearity phenomenon in the fuzzy linear regression setting. By incorporating $\alpha$-levels in the estimation procedure, a fuzzy ridge estimator which does not depend on the distance between fuzzy numbers is constructed.

The paper authored by Čubranić-Dobrodolac et al. [9] aims to examine a relationship between the speed and space assessment capabilities of drivers associated with the occurrence of road traffic accidents. The method is based on the implementation of the interval Type-2 Fuzzy Inference Systems (T2FIS) and tested on empirical data.

The paper authored by Carnero [10] studies segregation in health care waste management and aims to produce a classification of failure modes. It applies Failure Mode and Effects Analysis (FMEA), by combining an intuitionistic fuzzy hybrid weighted Euclidean distance operator, and the multi-criteria method Potentially All Pairwise RanKings of all possible Alternatives (PAPRIKA).

Wu et al. [11] propose the piecewise linear fuzzy geometric mean (PLFGM) approach to improve the accuracy and efficiency of estimating the fuzzy priorities of criteria. The PLFGM approach has been applied to the identification of critical features for a smart backpack design.

Kokkinos and Karayannis [12] perform a comparative analysis of low-carbon energy planning, evaluating different multicriteria decision-making methodologies. The methodologies are applied to a case study in the Thessaly region, Greece. The application of fuzzy goal programming (FGP) ranks four energy types in terms of feasibility, the stochastic fuzzy analytic hierarchical process (SF-AHP) evaluates the criteria and the F-TOPSIS technique assesses these criteria.

The paper authored by Abosuliman et al. [13] examines the decision-theoretical rough sets (DTRSs). The proposed model is based on the loss function of DTRSs. Based on the grade of positive, neutral and negative membership of fractional orthotriple fuzzy numbers (FOFNs), various methods are established for addressing the expected loss expressed in the form of FOFNs.

Chiu et al. [14] propose an interval fuzzy number (IFN)-based mixed binary quadratic programming-ordered weighted average (OWA) approach for forecasting the productivity of a factory. The methodology has been applied to a real case indicating that it was superior to several existing methods in terms of various metrics for evaluating the forecasting accuracy.

The paper authored by Pérez [15] examines technological tables in electrical discharge machining to determine optimal operating conditions for process variables. The study presents a methodology based on a fuzzy inference system aiming to assist in selecting the most appropriate manufacturing conditions in advance.

Gavalec et al. [16] aim to investigate the eigenvectors for maximum and minimum matrices with interval coefficients. In this study, the properties of EA/AE-interval eigenvectors are examined and characterized by equivalent conditions. Numerical recognition algorithms working in polynomial time have been described and the results are illustrated by numerical examples.

Tuan et al. [17] propose a new Mamdani Complex Fuzzy Inference System with Rule Reduction Using Complex Fuzzy Measures in Granular Computing (M-CFIS-R) along with fuzzy similarity measures, which are integrated with the form of granular computing. Experiments on various decision-making datasets demonstrate that the proposed M-CFIS-R performs better than M-CFIS.

The paper authored by Moslem et al. [18] aims to evaluate and prioritize the significant driver behavior factors related to road safety. The suggested method integrates the Best Worst Method (BWM) with triangular fuzzy sets for optimizing the complex decisionmaking problem.

As the Guest Editor of the Special Issue, I am grateful to all authors who contributed their articles. I would also like to express my gratitude to all reviewers for their valuable 
comments toward the improvement of the submitted papers. The goal of this Special Issue was to attract quality and novel papers in the field of "Fuzzy Optimization and Fuzzy Decision Making". It is hoped that these selected research papers will be found to be impactful by the international scientific community and that these papers will motivate further research on fuzzy techniques for solving complex problems in various disciplines and application fields.

Funding: This research received no external funding.

Conflicts of Interest: The authors declare no conflict of interest.

\section{References}

1. Zhang, H.; Zhang, Z.; Zhou, L.; Wu, S. Case-Based Reasoning for Hidden Property Analysis of Judgment Debtors. Mathematics 2021, 9, 1559. [CrossRef]

2. Wu, H.-C.; Tsai, H.-R.; Chen, T.-C.T.; Hsu, K.-W. Energy-Efficient Production Planning Using a Two-Stage Fuzzy Approach. Mathematics 2021, 9, 1101. [CrossRef]

3. Lefevr, N.; Kanavos, A.; Gerogiannis, V.C.; Iliadis, L.; Pintelas, P. Employing Fuzzy Logic to Analyze the Structure of Complex Biological and Epidemic Spreading Models. Mathematics 2021, 9, 977. [CrossRef]

4. Yiğit, V.; Demir, N.N.; Alidrisi, H.; Aydin, M.E. Elicitation of the Factors Affecting Electricity Distribution Efficiency Using the Fuzzy AHP Method. Mathematics 2021, 9, 82. [CrossRef]

5. Poczeta, K.; Papageorgiou, E.I.; Gerogiannis, V.C. Fuzzy Cognitive Maps Optimization for Decision Making and Prediction. Mathematics 2020, 8, 2059. [CrossRef]

6. Drakopoulos, G.; Kanavos, A.; Mylonas, P.; Pintelas, P. Extending Fuzzy Cognitive Maps with Tensor-Based Distance Metrics. Mathematics 2020, 8, 1898. [CrossRef]

7. Wu, H.-C.; Wang, Y.-C.; Chen, T.-C.T. Assessing and Comparing COVID-19 Intervention Strategies Using a Varying Partial Consensus Fuzzy Collaborative Intelligence Approach. Mathematics 2020, 8, 1725. [CrossRef]

8. Kim, H.; Jung, H.-Y. Ridge Fuzzy Regression Modelling for Solving Multicollinearity. Mathematics 2020, 8, 1572. [CrossRef]

9. Čubranić-Dobrodolac, M.; Švadlenka, L.; Čičević, S.; Trifunović, A.; Dobrodolac, M. Using the Interval Type-2 Fuzzy Inference Systems to Compare the Impact of Speed and Space Perception on the Occurrence of Road Traffic Accidents. Mathematics 2020, 8, 1548. [CrossRef]

10. Carnero, M.C. Waste Segregation FMEA Model Integrating Intuitionistic Fuzzy Set and the PAPRIKA Method. Mathematics 2020, 8, 1375. [CrossRef]

11. Wu, H.-C.; Chen, T.; Huang, C.-H. A Piecewise Linear FGM Approach for Efficient and Accurate FAHP Analysis: Smart Backpack Design as an Example. Mathematics 2020, 8, 1319. [CrossRef]

12. Kokkinos, K.; Karayannis, V. Supportiveness of Low-Carbon Energy Technology Policy Using Fuzzy Multicriteria DecisionMaking Methodologies. Mathematics 2020, 8, 178. [CrossRef]

13. Abosuliman, S.S.; Abdullah, S.; Qiyas, M. Three-Way Decisions Making Using Covering Based Fractional Orthotriple Fuzzy Rough Set Model. Mathematics 2020, 8, 1121. [CrossRef]

14. Chiu, M.-C.; Chen, T.-C.T.; Hsu, K.-W. Modeling an Uncertain Productivity Learning Process Using an Interval Fuzzy Methodology. Mathematics 2020, 8, 998. [CrossRef]

15. Luis Pérez, C.J. Using a Fuzzy Inference System to Obtain Technological Tables for Electrical Discharge Machining Processes. Mathematics 2020, 8, 922. [CrossRef]

16. Gavalec, M.; Plavka, J.; Ponce, D. EA/AE-Eigenvectors of Interval Max-Min Matrices. Mathematics 2020, 8, 882. [CrossRef]

17. Tuan, T.M.; Lan, L.T.H.; Chou, S.-Y.; Ngan, T.T.; Son, L.H.; Giang, N.L.; Ali, M. M-CFIS-R: Mamdani Complex Fuzzy Inference System with Rule Reduction Using Complex Fuzzy Measures in Granular Computing. Mathematics 2020, 8, 707. [CrossRef]

18. Moslem, S.; Gul, M.; Farooq, D.; Celik, E.; Ghorbanzadeh, O.; Blaschke, T. An Integrated Approach of Best-Worst Method (BWM) and Triangular Fuzzy Sets for Evaluating Driver Behavior Factors Related to Road Safety. Mathematics 2020, 8, 414. [CrossRef] 